\title{
Severe Weather: The New Challenge for the Planning of Greek Islands ${ }^{\dagger}$
}

\author{
Minas Gavalas \\ PhD Student on Department of Urban Planning \& Regional Planning, University of Thessaly, 38334 Volos, \\ Greece; minas1618@hotmail.com; Tel.: +30-697-923-1894 \\ + Presented at the 3rd EWaS International Conference on "Insights on the Water-Energy-Food Nexus", \\ Lefkada Island, Greece, 27-30 June 2018.
}

Published: 30 July 2018

\begin{abstract}
Climate change as a phenomenon of the recent years highly concerns scientists and governments. Global warming is the beginning of a domino effect with a lot and often huge consequences on the anthropogenic and natural environment. The present study aims at analyzing and understanding the driving factors, the impacts and the consequences of the climate change, while in parallel actions and policies are presented regarding its prevention. Additionally, an attempt is made to analyze data from 67 meteorological stations (Aegean Sea, Ionian Sea, Crete) to examine the occurrence and frequency of extreme weather phenomena and their consequences on the Greek Island region. Finally, conclusions are drawn and measures are proposed, aiming at the adjustment of the climate change planning on the Greek Island Area.
\end{abstract}

Keywords: climate change; island region; extreme weather phenomena; statistic meteorological analysis; planning

\section{Introduction}

Climate change is a phenomenon of great concern to the entire scientific community, but also to governments throughout the globe during the last years. Considering that global warming is the only manifestation of climate change is a common misconception of the public, often ignoring all the other aspects of it. This study aims at analyzing the impacts of climate change on all sectors. At the same time, it attempts to analyze all available meteorological data in order to highlight the impact of climate change and in particular the extreme weather phenomena on the Greek islands. The Greek Islands Area was chosen for being a unique place in the wider European area with many special features, and foremost for being a fragile area against climate change. Finally, the study attempts to propose measures to mitigate the effects of climate change and to improve the resilience of Greek Islands Area.

\section{Materials and Methods}

\subsection{Climate}

The climate is determined by the timeless set of conditions/phenomena that determine the weather, which are temperature, atmospheric pressure, wind, humidity, precipitation etc. However, the climate is quite fragile and influenced by external factors (circles of Milankovitch, solar activity and super nova explosions), internal factors (water cooling, greenhouse gases, El Nino, ice melting, anthropogenic, volcanic and seismic activity) and "horses" [1], which are large-scale disasters. The scale of impacts is as great as large is the scale of influence factors. Climate change affects natural processes (greenhouse enhancement, ozone depletion and enhancing the El Niño effect), water 
resources (rainfall reduction, degradation of subsoil and coastal ecosystems, strong evaporation of lakes, sea level rise, storm tides, sea shading, ice melting, icebergs and snowfall), flora and fauna (coral destruction, increase in fires, invasion of alien species, killing of fauna and flora, loss of vegetation due to extreme weather events, invasion of insects, disturbance of fauna, loss of habitats, migration and extinction of species), human activities (fisheries, agriculture, tourism, mining, transport and construction), human beings (indirect/direct effects of all above, increased mortality and morbidity, and Climate Migrants/Refugees) and the "explosion" of extreme weather phenomena [2], which add to the effects on all of the above.

\subsection{Study Area Description}

The present study focuses on the Greek Islands Area. Approximately 3053 islands are located in the Greek territory, covering $20 \%$ of the total $132,000 \mathrm{~km}^{2}$ Greek terrain. The islands' shoreline attributes to the $40 \%$ of the total $15,000 \mathrm{~km}$ of Greek shoreline, with $113 \mathrm{~m}$ of shoreline for every 1 $\mathrm{km}^{2}$ of terrain (while the global mean value is $5 \mathrm{~m}$ per $\mathrm{km}^{2}$ ) [3]. Within a zone of $50 \mathrm{~km}$ inshore is located the $85 \%$ of the total population, the $80 \%$ of industry the $90 \%$ of tourism and the entirety of fishing and fish farming [4], while in a coastal zone of $1-2 \mathrm{~km}$ inshore is located the $33 \%$ of the total population [5].

As a result the Greek Islands Area is particularly important from an economic point of view, as well as from an environmental-cultural one [6]. In particular, it was a cradle for the development of Greek Culture and a decisive factor, throughout its history, for its evolution. At the same time, its uniqueness for the plethora of islands, its natural heritage, both on its land and sea, the unique architecture of its settlements, which has been linked to the geomorphology, history and resources of each the unique landscape of the countryside, the local cultural features, the way of life and the unique experience of its inhabitants, who have developed a special relationship and connection of their economy with the element of the sea, is widely recognized [4-9]. It must also be highlighted the added value that this area offers in the country as "the blue economy, based on tourism that is the heavy industry of Greece, can be a driving force for the prosperity and growth of Greece" [10].

Despite its importance, uniqueness and recognition by the Greek Constitution, Greek Islands Area faces significant development problems, without the corresponding tools and policies both from the EU and Greek Government in order for them to be resolved. The problem arises from the dependence of the islands on the socio-economic development of the mainland, with all the phenomena resulting from it, such as migration, ineffective transport network, lack of inter-islands transport, etc. [6].

One of the main problems is the demographic and social destabilization. Many Greek islands face either the phenomenon of demographic change, with the demographic aging phenomenon being more intense, resulting in the desolation of many islands, or the form of the population explosion, not by the permanent population but by that of immigrants, which creates many social problems. At the same time, the rural population of the large and mountainous islands decrease, as the former rural population is concentrated in the coastal and urban areas, creating spatial and economic opposition, compared to the abandoned rural hinterland.

In the economic field, disruption of the local fabric and activity is observed, resulting in a shrinking production base, in particular in the primary sector. This stems from the shift to the opportunistic and seasonal economy, which is mostly based on tourism and on mass tourism. Also, for the needs of tourism infrastructure and later on for their operational needs, problems such as overexploitation of resources, issues of land use conflict, multiplexing, coastal development and the degradation or pollution of a particularly sensitive environment arose. However, tourism can be the only source of income for residents, but it leads to a bunch of additional problems in the islands [7].

Finally, with regard to development and spatial planning, intraregional inequalities are particularly intense and more important among the islands, as natural isolation does not allow for the diffusion of development, nor does it allow the easy interconnection of the islands to overcome many problems [6]. Also, the large fragmentation of the islands and their diversity, their design level and the lack of adoption of EEZ (Exclusive Economic Zone) pose problems in spatial, marine and coastal planning [11]. 


\subsection{Data Gathering Methodology}

To document climate change as well as the extreme weather phenomena in the Greek islands, it is necessary to analyze primary climatic data.

Initially, primary data were searched by the Hellenic Center for Marine Research and the Poseidon system through the floating stations it holds from their start of operations until 2015, as they could provide critical data such as wave height, for the rise of sea level and its temperature, apart from other climatic factors such as maximum, minimum and average temperature, rainfall, mean and maximum wind speeds. However, there are only four (4) of out of ten (10) stations, of which only one transmits data.

Since no conclusions could be drawn and no predictions could be made for the future from the HCMR network, the NMS was conducted to provide data for the period 2004-2015, for the mean, maximum and minimum temperature, precipitation, mean and maximum wind speed and atmospheric pressure. Although the NMH is the National Meteorological Service, its stations are restricted to points where airports are located. Additionally, besides the spatial problem, problems with the data were observed.

Finally, a solution for obtaining primary data was provided by the network of meteorological stations of the National Observatory of Athens, where data were collected for the start-up period of the station up to December 2016 for the mean, maximum and minimum temperature, rainfall, mean and maximum wind speeds. It should also be noted that in order to have a good sample of observations, only stations with the minimum 950 recordings were selected, while those who had periods with significant failures and therefore no data were rejected.

\subsection{Data Analysis Methodology}

Initially, station data were collected from the open database of the Meteo website. For each station, its location, date of commencement, and any technical problems, such as the absence of wind data, are reported. The data was received in .txt format per month and converted to Excel files for later processing and analysis. For each month, daily average temperature, maximum and its time, minimum and its time, maximum and minimum humidity, rainfall, average wind speed, maximum wind speed and time of recording and the main direction of the wind are reported.

Then, with the SPSS program, the statistical analysis was started, where for each station the statistical indices and the extremes for each analyzed variable were computed. Subsequently, the trend of the variables was attempted to be predicted. However, the SPSS program and its tools could not predict an important parameter, i.e., the periodicity/seasonality of the phenomena, so that the Determination Factor $\left(\mathrm{R}^{2}\right)$ was calculated below 0.03 and even up to 0.00 . Additionally, neither the time series forecasting tool could produce the desired results. Therefore, as a solution the GMDH software was used to predict time series. Therefore, it was possible to predict the changes of all the variables examined. However, the time space could not be common to all areas, as long as the need to predict the future requires long time series of data. For many stations predictions were made for up to 2020 and for others, with a smaller set of data, a smaller target year was achieved. The meteograms were then used to make climatic zoning, with temperature being the main factor for comparison because, due to locality, there were often no common meteograms for rainfall variables, average wind speeds and maximum speeds wind.

However, for the proper analysis, some indicators related to extreme weather events had to be calculated. The first and second indices were the number of days per month with precipitation. In this days, depending on the maximum temperature, rainfall days (with a maximum of more than 2.5 degrees Celsius), and snowfall days (with a maximum of below 2.5 degrees Celsius) were calculated. An important factor that is missing from our data, as we did not have the ten-day daily reports, is the rain rate, which it was replaced by monthly rain rate. It is the third index which was created, and it is the total millimeters of precipitation per month through the days with such phenomena. The fourth, fifth and sixth indices used for our research were temperature related. The fourth index is the days when the daily maximum exceeds 32 degrees and there was a heat wave, according to the National Observatory of Athens [12]. The fifth and the sixth indices are the counterparts of the former and are 
related to the frost, where, when the minimum daily temperature is below 0 degrees, there was frost, while for cases when the maximum does not exceed 0 degrees, there was total frost [12]. Frost and heatwaves constitute two phenomena that affect both human activity and living organisms, posing a threat to their integrity [12], but they also are important elements in the design of structures [13]. As far as the wind is concerned, a risk indicator has been created when the maximum wind gust exceeded $95.5 \mathrm{~km} / \mathrm{h}$.

In order to calculate the indexes and export the results to Excel per station, an appropriate code written in the MATLAB program was used. Along with the calculation of the indicators per month, the extreme values were also recorded per variable to identify the frequency of occurrence.

Finally, for phenomena such as hail, wind turbines and lightning, the European Severe Weather Database was used, as we could identify the spatial dimension of the phenomenon (whether it was in the island or continental area), so as to capture in the graphs the total annual number of occurrences of the phenomenon.

\section{Results}

The following Figures present indicative results of the data analysis, as described in the above section, regarding heatwave frequency and rate (Figure 1), frost frequency and rate (Figure 2) and rainfall frequency and rate (Figure 3).

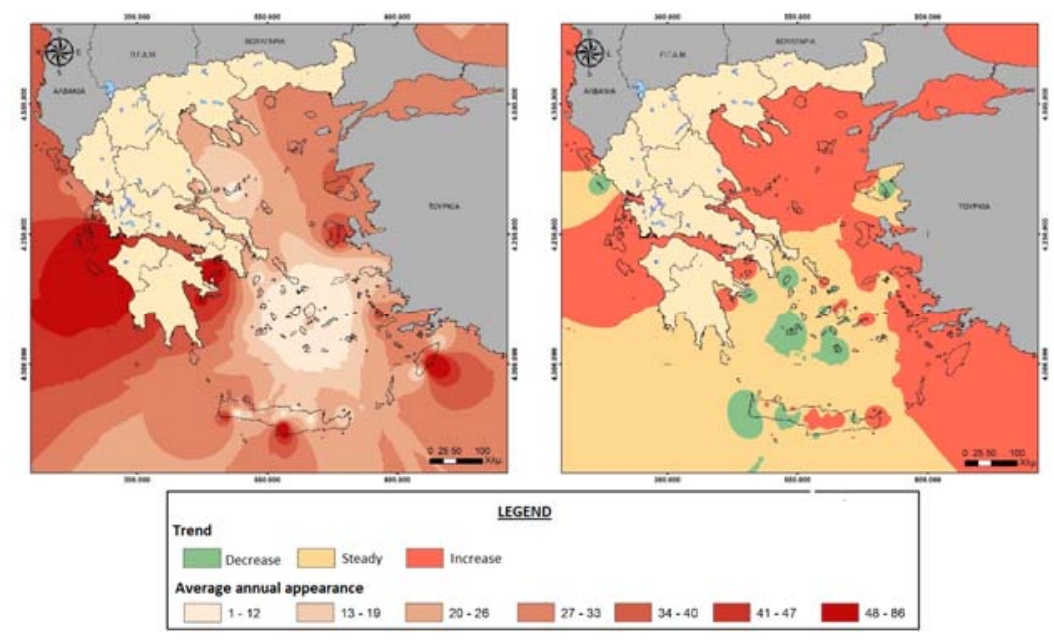

Figure 1. Heatwave frequency and rate.

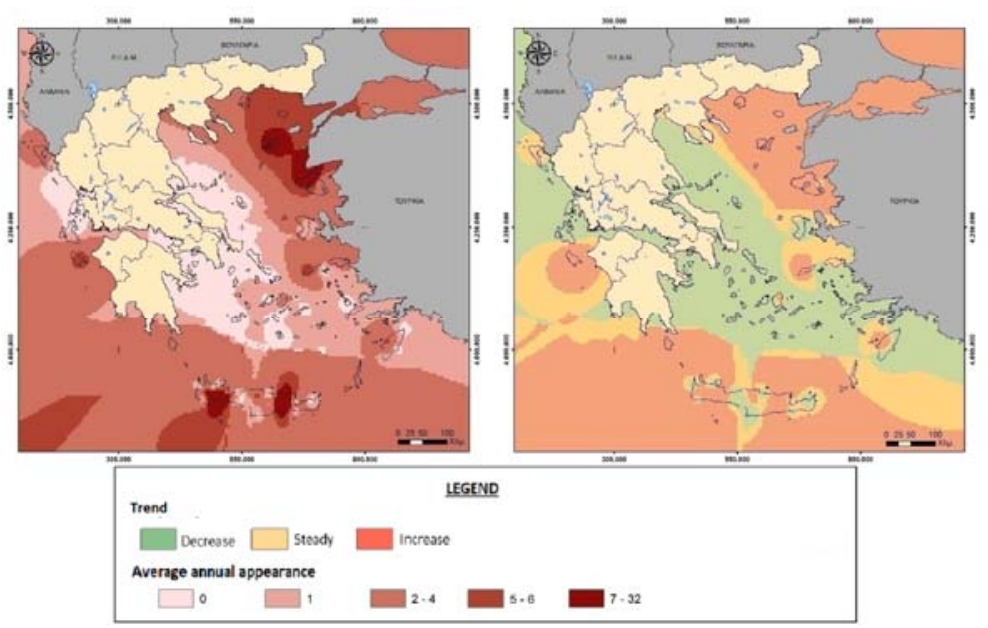

Figure 2. Frost frequency and rate. 


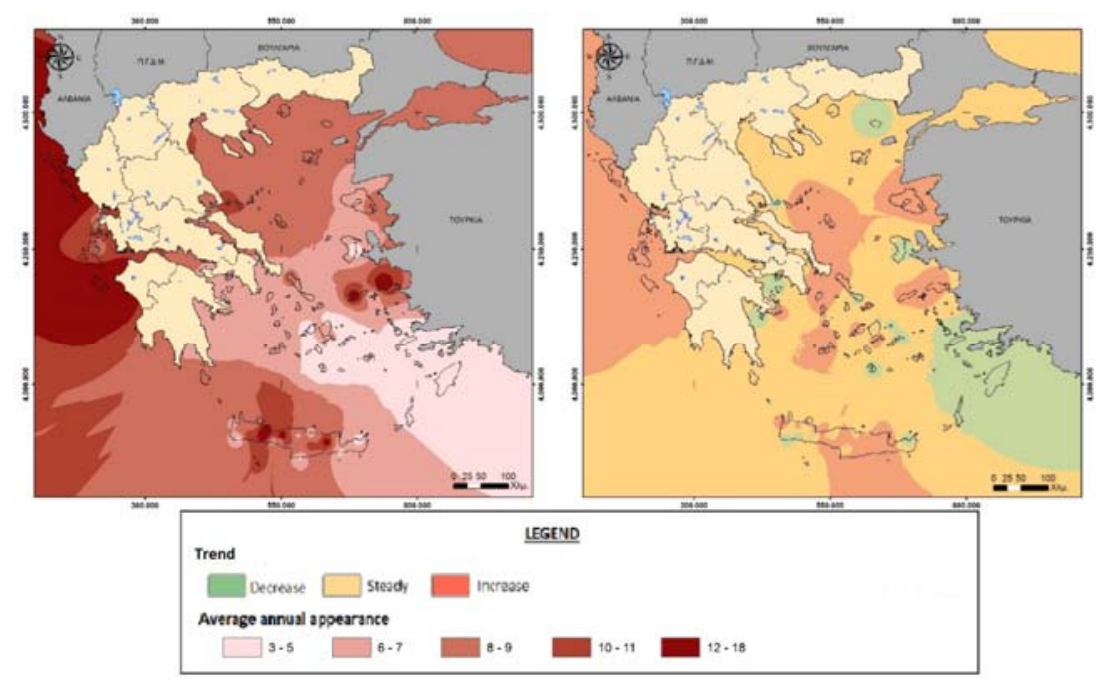

Figure 3. Rainfall frequency and rate.

As one can see, regarding heatwave trend, there is an increase in the north and east island area, while the south area presented a steady trend with areas of decreased heatwave trend. On the other hand, regarding frost trend, most of the central and east island area presented a decreased trend, while in the north-east and south, an increased trend was presented. Finally, regarding rainfall trend, in most of the island area a steady trend was presented.

From the overall observations seven conclusions emerge. Initially, there was an "explosion" of extreme phenomena in 2012, according to the data at all stations for that year, and the following year there was a significant decrease. This may be due either to the El Nino phenomenon or to the intense weather fronts or to the Fukushima disaster (2011), as huge quantities of radioactivity were released in the atmosphere with unknown impact on the climate. A similar event occurred in 1986 with the explosion at Chernobyl, when the following year (1987) the deadliest heatwave of modern history was occurred in Greece. In recent years, more and more frequent phenomena, such as snowfall and ice in coastal areas, have begun to occur in the southern segments. In addition, there is a large connection between the prevailing winds with the climate, as the climatic zoning revealed. Another strong interconnection was identified between the trend of warming phenomena with rainfall and winds. The heat effects results in a reduction of extreme wind observations and a total rainfall. Later on, the phenomenon of locality is quite serious. While in Mykonos and in the Tinos-Mykonos narrows, winds of intensity 10 Beaufort are very often, the station of Tinos does not record such values, due to the geomorphology of the city of Tinos, where the station is located. Similarly, in the case of Paros, where in Naoussa the intensity of the north wind is stronger than that recorded in Paroikia, where the station is located. Therefore, network expansion and a larger amount of data is needed to talk with enormous accuracy. Regarding the latter, we cannot conclude an overall increase or decrease in extreme phenomena. Each region is a particular entity, and this must be taken into account when designing. Exception is the phenomenon of wind turbines, hail and lightning, as these are seen to increase. This increase could be attributed to the increase in ground temperature (for wind turbines), the sea (for hydro-turbines), and haze (higher temperature in the atmosphere means larger clouds in height that combined with hot upward air currents favoring the creation of hail). Finally, a negative phenomenon that has been observed since ancient times is intensifying. In particular, western Greece receives the largest volume of precipitation, as opposed to the eastern one, which suffers from water scarcity. Observing the index of rain rate, it turns out that this phenomenon itself intensifies, increasingly leading to extreme values in intense rainfall.

\section{Conclusions-Suggestions}

The Greek Islands Area is a special place, directly affected by the weather and forgotten by the central policy of the mainland. In the above, the challenges of climate change and its impact are added. 
Rising sea levels, global warming, extreme weather extremes are increasing the disparities in this vulnerable area of Greece.

Island planning is thus called upon to be the cornerstone and core of a policy that will not further exacerbate existing problems, while at the same time anticipate and cope with the impacts of climate change. The new planning must therefore ensure that the islands of Greece are reinforced and avoid a demographic problem. Abandonment can come either from an aging population or from adverse living conditions such as exclusion from large centers, weather or lack of policy, lack of infrastructure or economic decline as involvement with only the tertiary sector makes the local economy vulnerable to a sudden change (for example, the destruction of extreme weather events complementing tourism or tourism infrastructure may weaken an area completely economically). In addition, it is necessary the establishment of land-use conflict regulators, resulting from economic development, to protect sensitive environmental areas such as many small wetlands, cultural monuments, coastal, agricultural and forest areas, architecture of the island countryside. Finally, the greatest demand is to "eliminate" the natural isolation of the islands and make them economically self-sufficient, as, opposed to inland space, in them it is hardly allowed the creation of synergies, development poles and interconnections. As a result, growth does not diffuse and remains at small, local levels.

Therefore, the greatest challenge of planning is the mix of spatial planning, environmental and cultural protection, economic development and, at the same time, the integration of climate change factors, and in particular extreme weather phenomena, with the aim of sustainability and the resilience of the island against all challenges.

Island planning is now confronted with climate change and must take all necessary steps to adapt it. Initially, it is necessary to plan from the municipal level up to the national level, taking into consideration all the necessary data regarding the local morphology, weather, economic activities and natural, cultural and architectural environment, with the involvement in the planning, of all stakeholders on a local scale. Also, the necessary integration of climate adaptation must be included. Academic research, as well as assistance from the Region Authorities, can play an important role. Therefore, the above competences and tools must be transferred from the state to the local level. In addition, local stakeholders can achieve better information of the local population, raising awareness and presenting the dangers arising from the phenomena they are confronted with. The development of local emergency, resilience and vulnerability plans against them can lead to better and safer living for island residents, coupled with early warning system. However, a better social policy is needed for vulnerable groups, especially in the health sector, as the climate will affect vulnerable people, such as the elderly, children, etc. who will most often be the victims of this change.

At the same time, it is necessary to implement the European model of planning, where spatial planning and economic development complement each other while at the same time working towards the wider development of the region. The bottom line is building local projects to better adapt to climate change as well as strengthening the directly affected sectors and activities. For example, as reported in the survey results, eastern Greece lacks rainfall and requires better use of water resources. This can be achieved, either through the use of rainwater collection tanks, at both municipal and residential level, or by enriching the underground aquifer. With regard to the latter, the presence of torrents, with seasonal flow or with a steep flow which could produce floods in the event of extreme rainfall, requires measures to protect the coastal area and the utilization of the water potential. This can be achieved by flood barriers that reduce flow, retain water, and enrich the underground aquifer, while retaining soil materials that can be exploited by the construction sector. The same must be done to protect the minimum agricultural land on the islands. In addition to the protection of agricultural land, it is necessary to use terraces that have multiple benefits as they retain the soil, drain excess water and create small habitats for many species or use of reeds to protect them from strong winds. In terms of supporting activities, especially agriculture, climate change is going to affect the production of agricultural products and possibly eliminate many species as they are not resilient to such extreme temperatures and water scarcity. However, research and financial support is needed to ensure that only local crops and agricultural products are preserved and given greater durability. Also, the use of integrated crop monitoring systems can bring greater efficiency and 
protection against extreme effects. Finally, archaeological sites and monuments need to be protected from the consequences of extreme events, as well as forest areas where the reduction of precipitation combined with the high temperatures and winds makes them vulnerable to fires, indirectly affecting residents, agriculture and tourism.

Regarding the economical pillar of Greece, it is considered necessary to extend the tourist season, as the new climatic conditions allow it, as well as the shift to an alternative form of tourism. At the same time, tourism infrastructure needs improvement in new climatic conditions. Green design, the use of wastewater for irrigation needs, and the use of better materials for construction and insulation will protect tourism infrastructure and help to provide a better and friendlier environmental tourism product. The same is required in the case of housing construction, which must be as energy and water autonomous as possible. Of course, all this requires respect for local architecture, especially in units/buildings located in traditional settlements.

However, extreme weather events and climate change are potentially an opportunity for energy disengagement from obsolete power plants (using coal and oil) by turning to renewable energy sources. Increasing wind intensity in many regions and solar energy can lead the islands to energy autonomy, create jobs and at the same time (in a proper placement) mitigate the tension of some phenomena such as waves in offshore parks or coastal infrastructure.

In conclusion, a complete redevelopment of Greece's spatial planning, urban planning, construction and development planning, and of the fragile island area (which is threatened by climate change, with drought, desertification, sea level rise, erosion and extreme weather phenomena) is necessary.

\section{References}

1. Guidens, A. Climate Change Policy; Metaichmio Press: Athens, Greece, 2009.

2. IPCC. Managing the Risks of Extreme Events and Disasters to Advance Climate Change Adaptation. A Special Report of Working Groups I and II of the Intergovernmental Panel on Climate Change (IPCC); Cambridge University Press: Cambridge, UK; New York, NY, USA, 2012.

3. Mperiatos, I., Papageorgiou, M. Spatial Planning in Fragile and Critical Areas; University of Thessaly Press: Volos, Greece, 2013.

4. Apostolakis, M. Protection and Integrated Coastal Zone Management: The International, European and National Context. Master's Thesis, University of Thessaly, Volos, Greece, 2012.

5. Stamatiou. E. Greece and the Mediterranean Area, Coastal Protection and Management, Comparative Approach; Series of Research Papers; University of Thessaly: Volos, Greece, 2014; pp. 123-144.

6. Zempelis, C.H.; Mperiatos, I. Coastal Areas-Islands-Problems \& Prospects; Workshop on Coastal \& Island Areas, Ministry of Environment: Athens, Greece, 2001; pp.15-28.

7. Gavalas, M. Integrated Management of Coastal Area: The Case of Paros. Bachelor's Diploma Thesis, University of Thessaly, Volos, Greece, 2015.

8. Tsaltas, G. Sustainability and Environment: The Islands Area in the 21st Century; I. Sideris Press: Athens, Greece, 2005.

9. Philippides, D. Modern Greek Architecture; Melissa Press: Athens, Greece, 1984.

10. European Committee Site. Available online: https://ec.europa.eu/greece/event/ 20170526_27_blue_economy_en (accessed on 4 June 2017).

11. Papageorgiou, M. Marine spatial planning and the Greek experience. Mar. Policy 2016, 74, 18-24.

12. Ziakopoulos, D., Frangkoulis, P. The Handbook of Meteorologist; National Meteorological Agency: Athens, Greece, 2015.

13. Machairas, V. Constructions Lectures; University of Thessaly, Department of Civil Engineering: Volos, Greece, 2016.

(C) 2018 by the author. Licensee MDPI, Basel, Switzerland. This article is an open access article distributed under the terms and conditions of the Creative Commons Attribution (CC BY) license (http://creativecommons.org/licenses/by/4.0/). 